\title{
Case Report \\ Eruptive Condyloma Accuminata after Initiation of Infliximab Treatment for Folliculitis Decalvans
}

\author{
Douglas C. Wu ${ }^{1}$ and Thomas G. Salopek ${ }^{1,2}$ \\ ${ }^{1}$ Division of Dermatology, Department of Medicine, University of Alberta, Edmonton, AB, Canada T6G $2 G 3$ \\ ${ }^{2}$ Division of Dermatology and Cutaneous Sciences, Department of Medicine, University of Alberta, 2-125 Clinical Sciences Building, \\ Edmonton, AB, Canada T6G 2G3
}

Correspondence should be addressed to Thomas G. Salopek; thomas.salopek@ualberta.ca

Received 2 September 2013; Accepted 4 November 2013

Academic Editors: I. D. Bassukas and K. Jimbow

Copyright (C) 2013 D. C. Wu and T. G. Salopek. This is an open access article distributed under the Creative Commons Attribution License, which permits unrestricted use, distribution, and reproduction in any medium, provided the original work is properly cited.

\begin{abstract}
We report a patient with recalcitrant folliculitis decalvans who was placed on infliximab due to failure to respond to numerous immunosuppressive drugs and antibiotics. After the second infusion of infliximab the patient reported a cutaneous eruption to the bilateral groin, penis, scrotum, perineum, and perianal region consistent with genital warts. The case highlights the need to inquire about a past or current history of genital or anal warts prior to the initiation of anti-TNF therapy, particularly with infliximab. If present, consideration should be given to concurrent antiwart therapy.
\end{abstract}

\section{Introduction}

Folliculitis decalvans (FD) is classified as a neutrophilic primary cicatricial alopecia [1]. Clinically, FD usually affects the scalp and is characterized by erythematous follicular pustules and tufted folliculitis with multiple hairs emerging from a single dilated follicular ostia. Colonies of Staphylococcus aureus are often present [2]. FD is often recalcitrant to multimodal antimicrobial and anti-inflammatory therapy. Recently, Mihaljevic and Driesch reported the successful use of infliximab for the treatment of therapy-resistant FD [3]. Included in the potential risks of anti-TNF therapy is the increased susceptibility to de novo or reactivated infections. In this report, we detail the occurrence of eruptive condyloma accuminata after initiation of infliximab treatment for therapy-resistant folliculitis decalvans. This finding highlights the need to review with patients before initiating anti-TNF therapy the possibility of having warts of any kind and in particular genital warts.

\section{Case Report}

The case concerns a 47-year-old man with a ten-year history of recalcitrant FD. He initially presented with erythematous follicular pustules and scarring alopecia to the scalp. Incidentally, he was also noted to have findings consistent with a mild hidradenitis suppurativa (HS) to the groin. A biopsy of the scalp revealed very dense collections of inflammatory cells noted in the superficial reticular dermis and papillary dermis with numerous bacterial colonies within dilated follicular ostia. He underwent extensive treatment including courses of oral minocycline, clindamycin, rifampin, and dapsone; topical clindamycin and antiseptic shampoos; clobetasol 0.05\% lotion and intralesional triamcinolone injections; acitretin and isotretinoin; prednisone, methotrexate, and mycophenolate mofetil. Unfortunately, these treatments and combinations thereof failed to produce a consistent remission and the patient remained on 15-20 mg daily of prednisone to achieve mediocre control of his condition.

In December 2012, infliximab infusions were initiated. Prior to commencement of infliximab therapy, it was ascertained that the patient was negative for HIV, hepatitis $\mathrm{B}$, and hepatitis C. Additionally, a tuberculin skin test was measured at $0 \mathrm{~mm}$ and a screening chest $\mathrm{X}$-ray revealed no evidence of tuberculosis. The patient received two infusions of infliximab at a dose of $5 \mathrm{mg} / \mathrm{kg}$ spaced 2 weeks apart. Shortly after his second infusion, the patient developed severe eruptive condyloma accuminata affecting his bilateral groin, penis, 


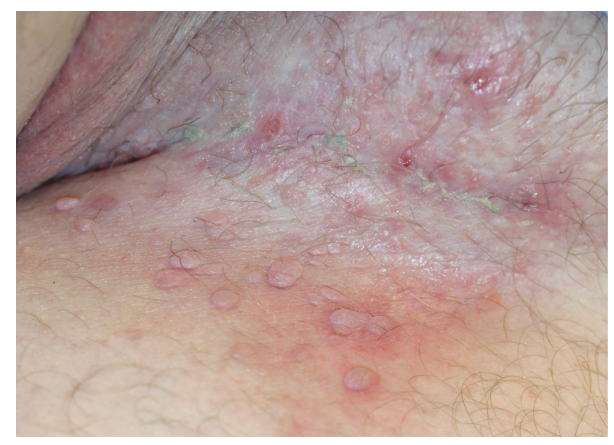

FIGURE 1: Multiple condyloma accuminata along the left inguinal fold.

scrotum, perineum, and perianal region (Figure 1). Infliximab infusions were discontinued. His warts are presently being treated with a combination of cryotherapy, imiquimod $5 \%$ cream, and podofilox $0.5 \%$ solution. With application of this combination, the condyloma resolved rapidly.

\section{Discussion}

Reports of human papilloma virus (HPV) infection associated with anti-TNF therapy have thus far been rare [46]. Almost all cases have been associated with infliximab, although one patient developed perianal condylomata in association with etanercept. Other viral infections frequently seen by dermatologists that may be exacerbated by antiTNF therapy include herpes zoster, primary varicella, and molluscum contagiosum $[7,8]$. Our patient did not have a known previous history of genital condylomata and repeated clinical examinations of his groin region (for mild HS) did not identify any evidence of disease prior to infliximab infusions. It is possible that he was an asymptomatic carrier of $\mathrm{HPV}$, which became clinically apparent only in the relatively immunosuppressed state of TNF inhibition. Of note, he was also on concurrent prednisone during his infliximab infusions and this may also have exacerbated the subsequent florid HPV eruption. Due to the risk of potential exacerbation of genital warts, patients should be informed and perhaps screened prior to initiation of anti-TNF therapy. If there is a history of verruca, consideration should be given to concurrent antiwart therapy.

\section{Conflict of Interests}

The authors declare no conflict of interests.

\section{References}

[1] E. A. Olsen, W. F. Bergfeld, G. Cotsarelis et al., "Summary of North American Hair Research Society (NAHRS): sponsored workshop on cicatricial alopecia, Duke University Medical Center, February 10 and 11, 2001," Journal of the American Academy of Dermatology, vol. 48, no. 1, pp. 103-110, 2003.
[2] C. M. Stefanato, "Histopathology of alopecia: a clinicopathological approach to diagnosis," Histopathology, vol. 56, no. 1, pp. 2438, 2010.

[3] N. Mihaljevic and P. von den Driesch, "Successful use of infliximab in a patient with recalcitrant folliculitis decalvans," Journal Der Deutschen Dermatologischen Gesellschaft, vol. 10, no. 8, pp. 589-590, 2012.

[4] A. Somasekar and R. Alcolado, "Genital condylomata in a patient receiving infliximab for Crohn's disease," Postgraduate Medical Journal, vol. 80, no. 944, pp. 358-359, 2004.

[5] C. Antoniou, M. G. Kosmadaki, A. J. Stratigos, and A. D. Katsambas, "Genital HPV lesions and molluscum contagiosum occurring in patients receiving anti-TNF- $\alpha$ therapy," Dermatology, vol. 216, no. 4, pp. 364-365, 2008.

[6] S. Georgala, A. C. Katoulis, A. Kanelleas, A. Befon, and C. Georgala, "Letter: Human papilloma virus and molluscum contagiosum lesions related to infliximab therapy for psoriasis: a case series," Dermatology Online Journal, vol. 18, no. 4, article 9, 2012.

[7] M. J. Shale, C. H. Seow, C. S. Coffin, G. G. Kaplan, R. Panaccione, and S. Ghosh, "Review article: chronic viral infection in the anti-tumour necrosis factor therapy era in inflammatory bowel disease," Alimentary Pharmacology and Therapeutics, vol. 31, no. 1, pp. 20-34, 2010.

[8] C. Cursiefen, M. Grunke, C. Dechant, C. Antoni, A. Jünemann, and L. M. Holbach, "Multiple bilateral eyelid molluscum contagiosum lesions associated with TNF $\alpha$-antibody and methotrexate therapy," The American Journal of Ophthalmology, vol. 134, no. 2, pp. 270-271, 2002. 


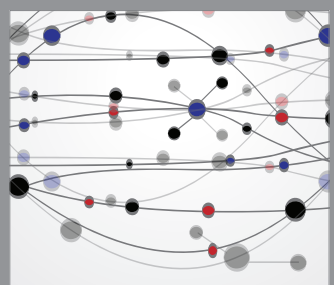

The Scientific World Journal
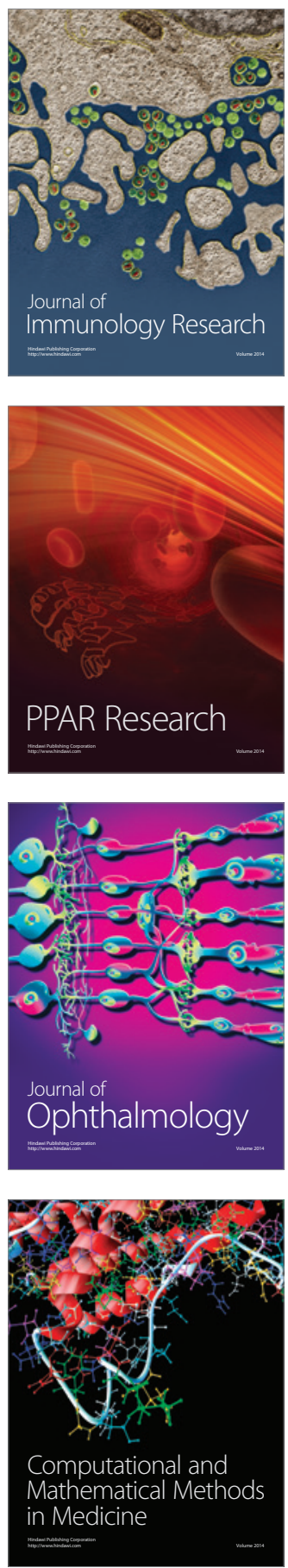

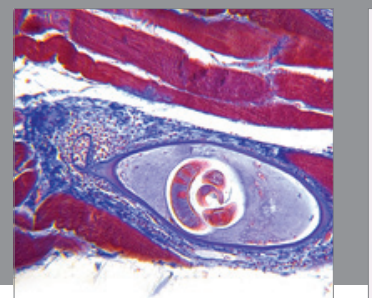

Gastroenterology

Research and Practice
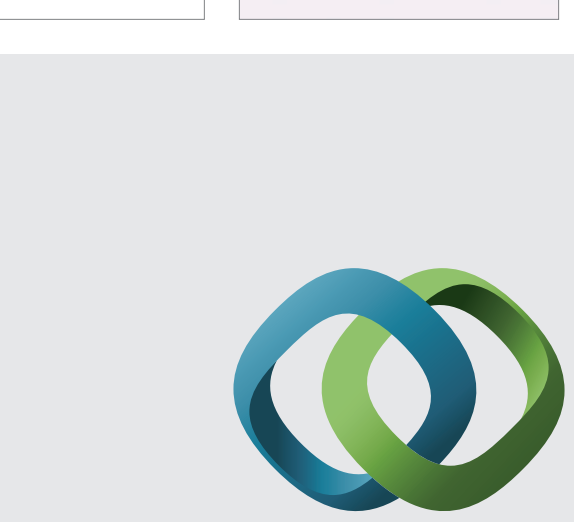

\section{Hindawi}

Submit your manuscripts at

http://www.hindawi.com
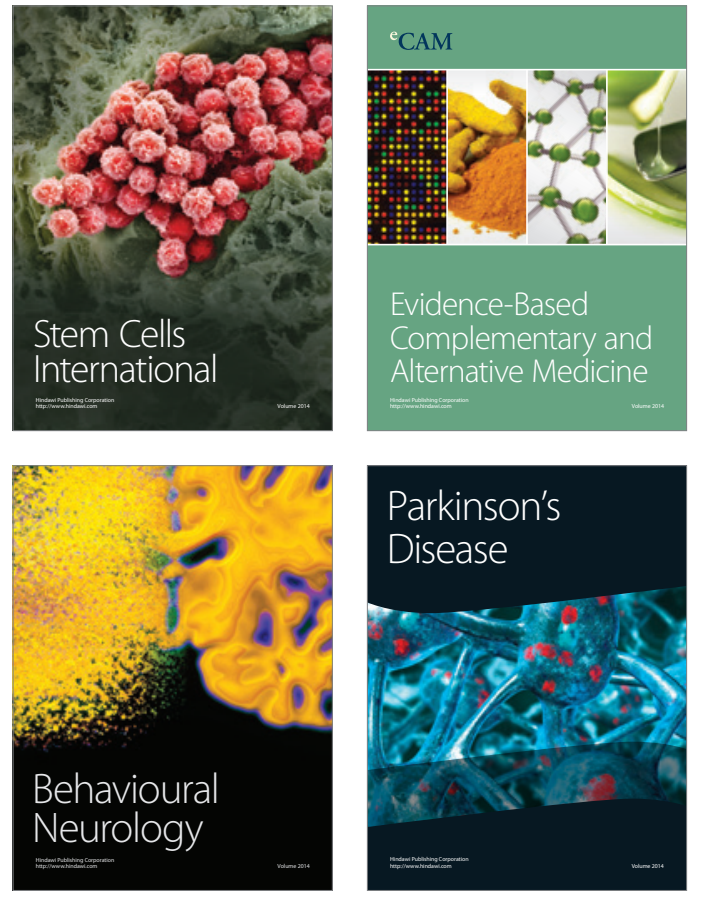
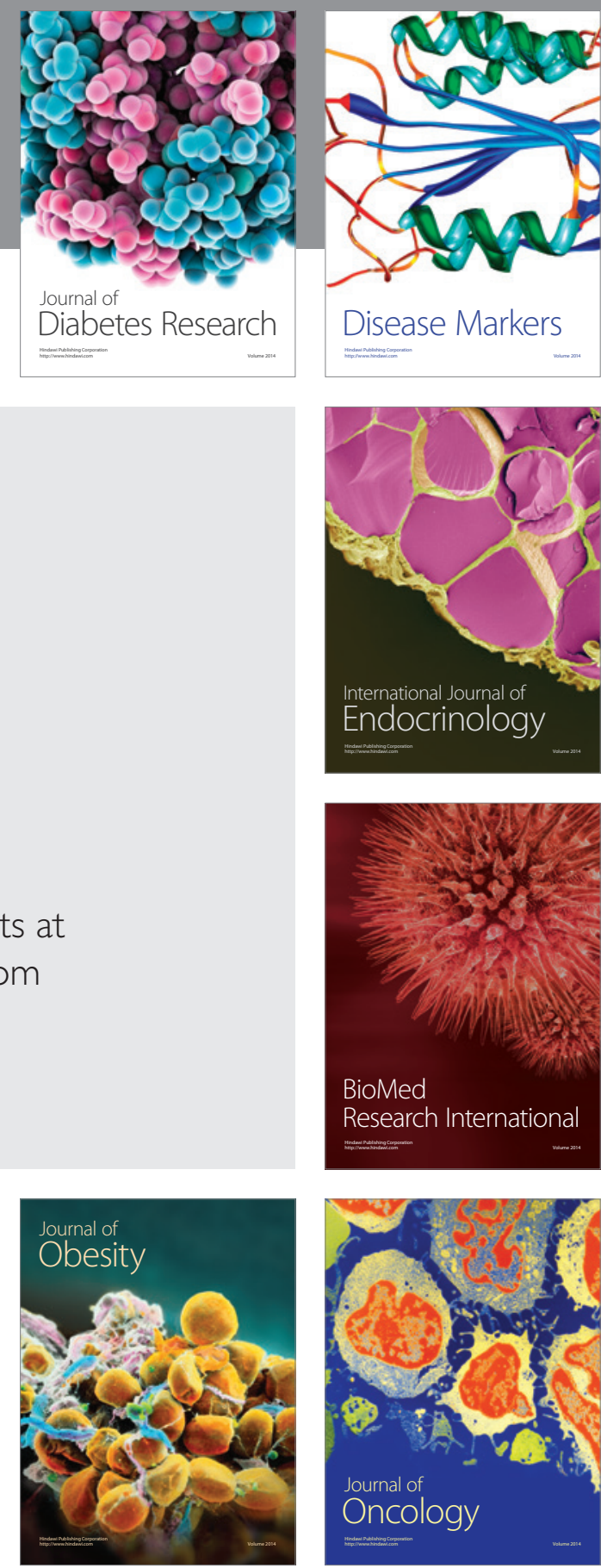

Disease Markers
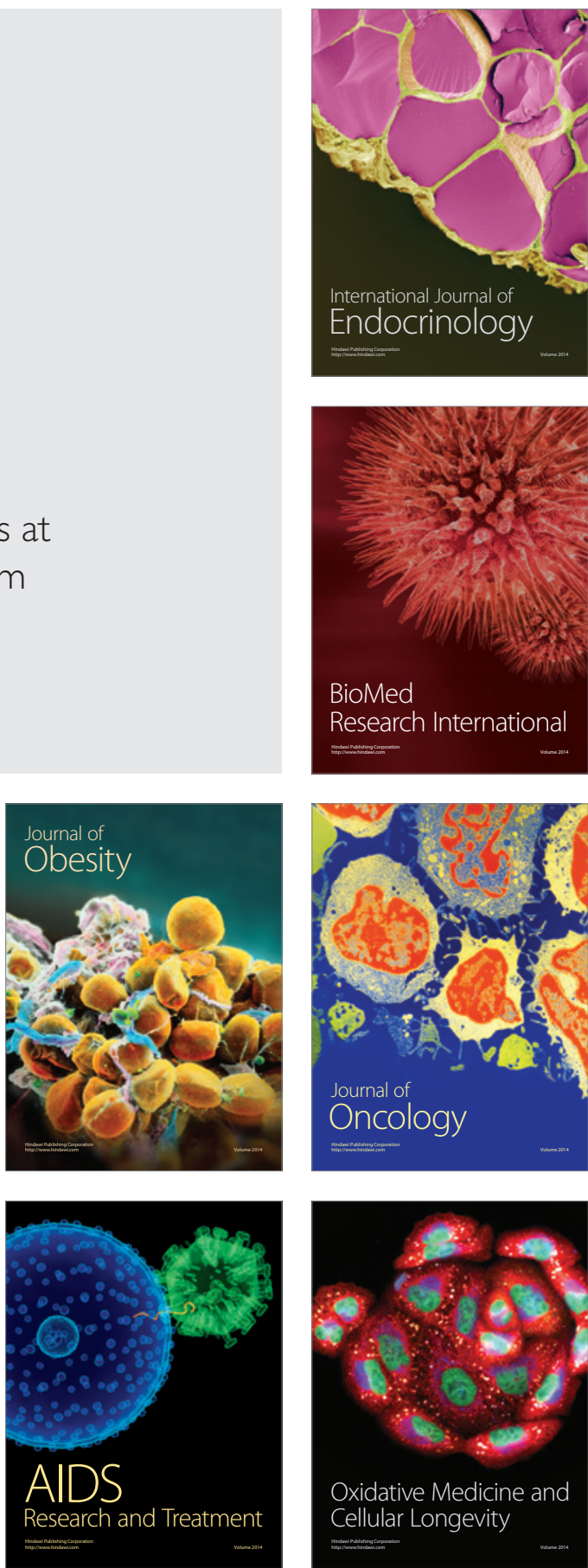